University of Windsor

Scholarship at UWindsor

\title{
Employment Discrimination Faced by Muslim Women Wearing the Hijab: Exploratory Meta-Analysis
}

Sofia Ahmed

Uwindsor, ahmed164@uwindsor.ca

Kevin Gorey

University of Windsor

Follow this and additional works at: https://scholar.uwindsor.ca/uwilldiscover

Ahmed, Sofia and Gorey, Kevin, "Employment Discrimination Faced by Muslim Women Wearing the Hijab: Exploratory Meta-Analysis" (2020). UWill Discover Undergraduate Conference. 145.

https://scholar.uwindsor.ca/uwilldiscover/2020/online/145

This Event is brought to you for free and open access by the Conferences and Conference Proceedings at Scholarship at UWindsor. It has been accepted for inclusion in UWill Discover Undergraduate Conference by an authorized administrator of Scholarship at UWindsor. For more information, please contact scholarship@uwindsor.ca. 


\begin{abstract}
With the recent increase in global immigrant and refugees, there are many Muslim women seeking employment in Western countries. However, those who wear the hijab often struggle to secure work, which may be in part due to Islamophobic discrimination. However, there is limited research on this phenomenon. The current study tested the hypothesis that Muslim women who wear the hijab are disadvantaged in employment processes relative to their counterparts who do not wear the hijab. A meta-analysis synthesized the findings of seven studies published between 2010 and 2019. The estimate was sample-weighted and pooled among experimental studies that were deemed the most internally valid. The findings suggest that the chances of being hired and so gainfully employed were $40 \%$ lower among Muslim women wearing the hijab than they were among, otherwise similar, Muslim women not wearing the hijab: relative risk $(\mathrm{RR})=0.60$ within a $95 \%$ confidence interval $(\mathrm{CI})$ of $0.54,0.67$. This religion-based discrimination effect was deemed hugely significant in human, public health, and policy senses. Immigration trends suggest that millions of Muslim women in the West likely experienced such employment discrimination between 2010 and 2019, and millions will likely suffer in the same way if policy status quos are retained. Based on participants' responses, much of the employment discrimination experienced by Muslim women who wear the hijab is due largely to potential employers' prejudicial reactions to the hijab itself. Practice and policy implications and future research needs are discussed.
\end{abstract}

Keywords: Employment, discrimination, hijab, headscarf, Muslim women 